\section{The effect of using interactive communication tools in adults with type-2 diabetes}

\author{
Sofia Akritidou, ${ }^{1}$ \\ Gitte Reventlov Husted, ${ }^{2}$ \\ Kyriakos Kazakos, \\ Kasper Olesen ${ }^{2}$ \\ ${ }^{1}$ Alexander Technological Educational \\ Institute (ATEITH) of Thessaloniki, \\ Greece; ${ }^{2}$ Steno Diabetes Center A/S, \\ Diabetes Management Research, \\ Gentofte, Denmark
}

\begin{abstract}
The purpose of this study was to investigate whether glycaemic control and diabetes self-management could be improved in patients with type- 2 diabetes following education using the EMMA dialogue tools facilitated by a health care professional. Glycosylated haemoglobin (HbAlc) and Summary of Diabetes Self Care Activities (SDSCA) scores were collected at baseline and three months after the intervention from 22 participating patients. Participants significantly improved self-reported foot care $(\mathrm{P}<0.001)$ and exercise $(\mathrm{P}<0.001)$ whereas no significant changes were found in HbA1c $(\mathrm{P}=0.606)$ blood sugar measurements $(\mathrm{P}=0.213)$, and diet $(\mathrm{P}=0.061)$. In conclusion, the dialogue tools had a positive effect by improving diabetes self-management regarding foot care and exercise. The purpose of this study was to investigate whether glycaemic control and diabetes self-management could be improved in patients with type- 2 diabetes following education using the EMMA dialogue tools facilitated by a health care professional. Glycosylated haemoglobin (HbAlc) and Summary of Diabetes Self Care Activities (SDSCA) scores were collected at baseline and three months after the intervention from 22 participating patients. Participants significantly improved self-reported foot care $(\mathrm{P}<0.001)$ and exercise $(\mathrm{P}<0.001)$ whereas no significant changes were found in HbAlc $(\mathrm{P}=0.606)$ blood sugar measurements $(\mathrm{P}=0.213)$, and diet $(\mathrm{P}=0.061)$. In conclusion, the dialogue tools had a positive effect by improving diabetes self-management regarding foot care and exercise.
\end{abstract}

\section{Introduction}

Self-management in patients with type2 diabetes is crucial to delay or prevent complications such as end-stage chronic kidney disease, blindness and amputations. $^{1-4}$ However, only $25 \%$ of patients adhere to recommendations related to medicine, diet and exercise. ${ }^{5}$ Accordingly the recommended approach to support patients to diabetes self-management has recently changed from a compliance-expecting approach in favour of an individualized, patient-centred approach. ${ }^{6}$ Studies indicate that changes in usual patient-provider collaboration influence patients' ability to selfmanage, e.g., when health care professionals (HCP) use dialogue tools and go through communication skills training. ${ }^{7}$

In response to this we tested a patientcentred education program based on interactive dialogue tools for one-to-one consultations; the EMMA program (Empowerment, Motivation, and Medical Adherence). ${ }^{8,9}$ The program intends to use dialogue to enhance intrinsic motivation for health behaviour changes and to improve medical adherence in the patients. ${ }^{9}$ The tools consists of visual and tangible materials and gives the health care professionals an opportunity to step away from their role as traditional medical authorities. ${ }^{10}$ The tools are supported by pictures, illustrations and statement cards with short sentences for promoting reflection and dialogue. The aim of the EMMA exercises is to support selfmanagement by exploring patient concerns and challenges, enabling knowledge exchange, and supporting goal-setting and action-planning. ${ }^{11}$ The program is flexible as the health care professional has the opportunity to select the most appropriate exercises for each specific consultation depending on the needs and wishes of the individual patient. In a Danish pilot test, the EMMA education program led to improved glycemic control (HbA1c) compared to usual consultations $(\mathrm{n}=44 ; \mathrm{P}=0.047) .{ }^{8}$ The purpose of this study was to investigate if glycemic control and motivation for diabetes self-management were improved following one session of a short version of the EMMA education program.

\section{Materials and Methods}

\section{Participants}

The study took place at the Aretaeus Diabetes Center, Greece, between January 2014 and September 2014. The inclusion criteria for participation in the study were: i) duration of type- 2 diabetes $>1$ year; and ii) low medication adherence indicated by a $\geq 2$ score on the Morisky medication adherence scale. ${ }^{12}$ The exclusion criteria for the study were: i) $<18$ years of age; ii) inade-
Correspondence: Kasper Olesen, Steno Diabetes Center, Niels Steensens Vej 6, 2820 Gentofte, Denmark. Tel.: +45.30793439.

E-mail:koee@steno.dk

Key words: Patient education; health behaviour; EMMA; type-2 diabetes.

Contributions: SA and KK designed the study. Supervised by KK, SA carried out the intervention, collected the data, and completed preliminary analyses. $\mathrm{KO}$ and $\mathrm{GH}$ analysed the data and drafted a manuscript. All authors contributed to interpretation of the results and approved the final version of the manuscript.

Conflicts of interests: $\mathrm{KO}$ and $\mathrm{GH}$ are employed by Steno Diabetes Center A/S, a research hospital working in the Danish National Health Service and owned by Novo Nordisk A/S. Steno Diabetes Center receives part of its core funding from unrestricted grants from the Novo Foundation and Novo Nordisk.

Received for publication: 15 July 2016. Revision received: 15 December 2016. Accepted for publication: 9 January 2017

This work is licensed under a Creative Commons Attribution NonCommercial 4.0 License (CC BY-NC 4.0).

(C) Copyright S. Akritidou et al., 2017

Licensee PAGEPress, Italy

Nursing Reports 2017; 7:6155

doi:10.4081/nursrep.2017.6155

quate reading or writing skills; iii) coexistence of psychiatric disease; iv) limited patient mobility. Among 24 eligible patients we invited, 22 agreed to participate and were enrolled in the study.

\section{Data collection}

The patients completed a clinical session at baseline where clinical, somatometric data, as well as medical history were collected. This was followed by a health care professional led EMMA education session (duration 30 to 40 minutes). For the purpose of this study, we used of a short form of the EMMA tools containing 12 interactive dialogue tools, for instance; 'My Day' where the aim is to establish close contact with patients whilst gathering valuable information in a way that is guided by the patients, 'My Medication' to gain insight into patients' daily lives in order to review and correct any immediate errors and inappropriate issues in patients medication regimes, 'Treating type-2 diabetes', in order to discuss in more detail the treatment patients receives and the changes that may have to 
be made, 'Symptoms of high and low blood sugar', where the aim is to talk about and made patients aware of the typical symptoms of high and low blood sugar, 'Prevention of long-term complications' to take a more detailed look of the areas that can be affected by long-term complications and how to prevent and/or relieve them. ${ }^{8,9}$

Glycosylated haemoglobin was determined at baseline and after 3 months using the method of high performance liquid chromatography. To evaluate patient selfcare before and after the intervention, frequency of self-care behaviours during the last week was assessed with the Summary of Diabetes Self-Care Activities scale (SDSCA), a self-reported 11-item questionnaire at baseline and three months after the intervention. ${ }^{13}$ The self-care behaviours were related to diet ("How many days during the last week did you follow your nutrition programme?'), exercise ('How many days, during the last week, did you engage in continuous physical activity for at least 30 minutes?'), blood sugar measurements ('How many days, during the last week, did you measure your blood sugar?'), and foot care (How many days, during the last week, did you check your feet?'). Self-care to diet was evaluated with 5 questions whereas exercise, foot care and blood sugar measurements were assessed with two questions each. An increase in total sum scores from baseline to follow-up would indicate an increase in diabetes self-management.

\section{Statistical analysis}

The percentage of women and the mean, standard deviation, minimum- and maximum values for quantitative characteristics (age, weight, height, BMI, duration of diabetes) were calculated. The mean, standard deviation, min-, and max values for each scale of the questionnaire were also calculated. For comparison of values before and after standard paired t-tests were used. In all tests performed, the level of significance was set at 0.05 . All data were analysed using SAS 9.2.

\section{Results}

The intervention group consisted of 22 patients (68\% women) with type- 2 diabetes. Table 1 shows characteristics of the participants.

The mean age for the intervention group was 68 years (40-84), mean weight $77.3 \mathrm{~kg}$ (41.4-130.0), mean height 1.62 meters (1.46-1.78), mean BMI 29.3 (18.4-48.1), and mean duration of the disease was 13.2 years (2.0-31.0).

Table 2 shows the results from paired $t-$ tests comparing measures from before and after the intervention.

The mean value of HbAlc before the intervention was $7.08 \%$ and remained unchanged $(7.05 \%)$ following the intervention. The change was, however, not statistically significant. Statistically significant improvements were found in scores on exercise $(\mathrm{P}<0.001)$ and foot care $(\mathrm{P}<0.001)$. For score on the diet scale and daily blood sugar measurements we did not find any changes.

Table 1. Pre-intervention participant characteristics $(n=22)$.

\begin{tabular}{lcccc} 
Pre-intervention value & \multicolumn{3}{c}{ Variable } & Max \\
& Mean & Standard deviation & Min & 84 \\
Age (year) & 68 & 12 & 40 & 31.0 \\
Duration of disease (year) & 13.2 & 9.9 & 2.0 & 1.78 \\
\hline Height (meter) & 1.62 & 0.09 & 1.46 & 130.0 \\
Weight (kilo) & 77.3 & 23.6 & 41.4 & 48.1 \\
\hline BMI (weight/height ${ }^{2}$ ) & 29.3 & 7.8 & 18.4 &
\end{tabular}

Table 2. Paired t-test for difference. Pre-intervention versus post-intervention $(n=22)$.

\begin{tabular}{|c|c|c|c|c|c|c|c|c|c|}
\hline \multirow[t]{2}{*}{ Variable } & \multicolumn{4}{|c|}{ Pre-intervention value } & \multicolumn{4}{|c|}{ Post- intervention value } & \multirow[t]{2}{*}{$\mathbf{P}$} \\
\hline & Mean & Standard deviation & Min & Max & Mean & Standard deviation & Min & Max & \\
\hline HbAlc & 7.08 & 1.15 & 5.20 & 10.00 & 7.05 & 1.09 & 5.20 & 9.80 & 0.606 \\
\hline Foot care & 1.57 & 1.31 & 0.00 & 4.00 & 2.70 & 0.95 & 1.00 & 4.50 & $<0.001$ \\
\hline Blood sugar measurements & 4.00 & 1.78 & 0.50 & 7.00 & 4.09 & 1.69 & 0.50 & 7.00 & 0.213 \\
\hline Diet & 3.43 & 1.29 & 1.40 & 6.40 & 3.47 & 1.19 & 1.60 & 6.40 & 0.329 \\
\hline Exercise & 1.82 & 1.68 & 0.00 & 5.50 & 2.36 & 1.77 & 0.00 & 5.50 & $<0.001$ \\
\hline
\end{tabular}

\section{Discussion and Conclusions}

In this pilot study, the use of interactive dialogue tools in combination with the use of the principles from motivational interviewing was found to be associated with improvements in foot care and exercise among patients with type-2 diabetes. However, improvements in diet and frequency of blood-sugar measurements were not found. A minor and insignificant decrease in $\mathrm{HbA} 1 \mathrm{c}$ was found following the intervention. Those results indicate that one session of EMMA education with the use of interactive dialogue tools may enhance the motivation for diabetes self-management among patients with type- 2 diabetes in this study.

The improvements in foot care and exercise are important outcomes. Studies have shown that health education interventions focusing on self-management are capable of preventing or delaying disease complications. $^{3,4}$ The use of different dialogue tools seemed to educate and engage patients in changing habits of foot care and exercise. However, no changes in diet were identified. This point to an assumption that changes in diet habits may require more education sessions, perhaps even taking place over a longer period of time. ${ }^{14}$

The assumption was that the HbAlc levels would improve through a more appropriate diet and increased exercise. The failure to see improvements in HbAlc levels could, however, be associated with the $\mathrm{HbA1c-levels} \mathrm{prior} \mathrm{to} \mathrm{the} \mathrm{intervention} \mathrm{as}$ they were not particularly high (mean = 7.08). Likewise, lack of changes in bloodsugar measurements might be explained by a relatively high number of daily measurements (mean $=4.00$ ) prior to the intervention, leaving smaller room for improvement.

Limitations to the study include the small sample size, which offered low statistical power. The one-session education also gave limitations to the expected outcomes. A more comprehensive education could possibly have improved the benefits of the intervention. However, the study also had important assets. The Greek setting gave opportunity to test a short version of the EMMA education program among partici- 
pants with a cultural background different from the one in which the program was developed and tested firstly. Furthermore, even with a relatively low number of participants we were able to identify highly significant differences. Finally the costs of implementing one-session health education (short version) may seem more feasible in clinics where lack of time to expand usual consultations or financial challenges are present needed.

In conclusion, the use of the interactive dialogue tools led to improvements in diabetes self-management in Greek patients with type-2 diabetes. Despite notable limitations we identified important improvements. These promising results need further testing in a larger scale.

\section{References}

1. Brown SA. Interventions to promote diabetes self-management: state of the science. Diabet Educ 1999;25:52-61.

2. Norris SL, Lau J, Smith SJ, et al. Selfmanagement education for adults with type 2 diabetes: a meta-analysis of the effect on glycemic control. Diabet Care 2002;25:1159-71.

3. Gary TL, Genkinger JM, Guallar E, et al. Meta-analysis of randomized educational and behavioral interventions in type 2 diabetes. Diabet Educ 2003;29: 488-501.

4. Deakin T, McShane CE, Cade JE, Williams RD. Group based training for self-management strategies in people with type 2 diabetes mellitus. Cochrane Database Syst Rev 2005;(2): CD003417.

5. McNabb WL. Adherence in diabetes: can we define it and can we measure it? Diabet Care 1997;20:215-8.

6. Inzucchi SE, Bergenstal RM, Buse JB, et al. Management of hyperglycemia in type 2 diabetes: a patient-centered approach: position statement of the American Diabetes Association (ADA) and the European Association for the Study of Diabetes (EASD). Diabet Care 2012;35:1364-79.

7. Haywood K, Marshall S, Fitzpatrick R. Patient participation in the consultation process: a structured review of intervention strategies. Patient Educ Counsel 2006;63:12-23.
8. Andrésdóttir G. Improving adherence, prediction and prognosis in diabetes with emphasis on nephropathy. Frederiksberg SL Graphic, Denmark: University of Copenhagen; 2014.

9. Varming AR, Hansen UM, Andresdottir $\mathrm{G}$, et al. Empowerment, motivation, and medical adherence (EMMA): the feasibility of a program for patient-centered consultations to support medication adherence and blood glucose control in adults with type 2 diabetes. Patient Prefer Adher 2015;9:1243-53.

10. Bandura A. Self-efficacy: toward a unifying theory of behavioral change. Psychol Rev 1977;84:191-215.

11. Miller WR, Rollnick S. Motivational interviewing: preparing people for change. 2nd ed. New York: Guilford Press; 2002.

12. Morisky DE, Green LW, Levine DM. Concurrent and predictive validity of a self-reported measure of medication adherence. Med Care 1986;24:67-74.

13. Toobert DJ, Hampson SE, Glasgow RE. The summary of diabetes self-care activities measure: results from 7 studies and a revised scale. Diabet Care 2000;23:943-50. 